Journal of Applied Fluid Mechanics, Vol. 9, Special Issue 2 pp. 177-188, 2016.

Selected papers from the XIIth Franco - Quebec Inter-University

Symposiumon Thermal Systems -2015

Available online at www.jafmonline.net, ISSN 1735-3572, EISSN 1735-3645.

DOI: $10.36884 /$ jafm.9.SI2.25770

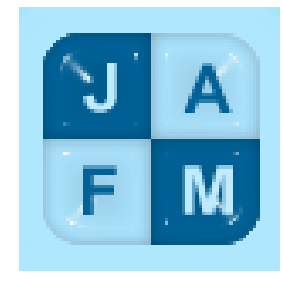

\title{
Experimental Study of Premixed Flame Methane-Air using a Fine Wire Compensed Thermometry
}

\author{
M. S. Boulahlib ${ }^{1 \dagger}$ and M. A. Boukhalfa ${ }^{2}$ \\ ${ }^{1}$ Laboratory of Engineering Transportation and Environment, University Mentouri \\ Constantine, Ain El Bey Road, 25017, Algeria \\ ${ }^{2}$ INSA-CORIA, Route de l'Université, Technopole du Madrillet, Saint Etienne du Rouvray 76810 cedex \\ France
}

†Corresponding Author Email:msboulahlib@gmail.com

(Received October 8, 2015; accepted December 10, 2015)

\begin{abstract}
An experimental procedure with post processing to measure the temperature fields in premixed turbulent flame is presented. Temperature measurements were performed on turbulent premixed flame $\mathrm{CH}_{4}$-air with an equivalence ratio $\varphi=0.6 \div 1.3$. It utilizes the Fine Wire Compensated Thermometry (FWCT) technique. Using fine wire thermocouples for a temporal resolution of the measurement in high temperature requires specific treatment of these values. When the temperature of the environment is high, the radiant loss becomes important. The temperature measured by the hot junction is less than the environment temperature.

These losses are estimated by one model, which make it possible to correct the difference between thermocouple temperature and gas temperature. Temperature measure by Fine Wire Compensated Thermocouple requires knowledge of flow velocity, the experimental conditions, the acquisition parameters (sampling frequency) for post-processing. In addition to this, the catalytic effect was incorporated to the final balance equation. The flame temperature and its fluctuations are analyzed by digital processing algorithms. Measurements validation made by the FWCT technique with optical measurement methods (Rayleigh scattering) shows a good agreement.
\end{abstract}

Keywords: Experimental; Premixed combustion; Fine wire; Compensation; Thermometry.

\section{NOMENCLATURE}

$\begin{array}{ll}\text { c } & \text { progress variable } \\ C_{D} & \text { blocking coefficient } \\ C p & \text { gas conductivity } \\ D & \text { burner diameter } \\ \mathrm{d} & \text { wire diameter } \\ \mathrm{dh} & \text { hole diameter of grid } \\ \mathrm{dx} & \text { unit length } \\ \mathrm{H} & \text { flame heights } \\ \mathrm{M} & \text { distance between holes } \\ \mathrm{R} & \text { wire radius, burner radius } \\ \mathrm{T} & \text { flame temperature } \\ \mathrm{T}_{\mathrm{C}} & \text { wire temperature }\end{array}$

1. INTRODUCTION

A better understanding of turbulent combustion is a

$\begin{array}{ll}\mathrm{Tg} & \text { gas temperature } \\ \mathrm{t} & \text { time } \\ \mathrm{U}, \mathrm{V} & \text { radial and axial velocity } \\ \mathrm{U}_{0} & \text { radial velocity on axis flow } \\ \mathrm{u}^{\prime}, \mathrm{v}, & \text { radial and axial velocity fluctuation } \\ \mathrm{u}^{\prime} / \mathrm{U} & \text { turbulence intensity } \\ \mathrm{y}, \mathrm{z} & \text { vertical axis } \\ \varepsilon & \text { gas emissivity } \\ \lambda & \text { wire conductivity } \\ \rho & \text { wire density } \\ \tau_{\mathrm{cv}} & \text { time constant }\end{array}$

capital interest in the field of reactive flows, by the complexity of the phenomena involved but also because widespread in our lives. Studies of 
turbulent flames are various domestic and technological applications such as burners (Al abdelli et al. 2015, Keramiotisa et al. 2015), engines (Shahrir et al. 2008, Krishna and Mallikarjuna 2010, Bakhsan and Shadaei 2013), gas turbines (Buchlin 2011). The Bunsen burner is very widely applied in industrial or domestic domains. Knowledge of the structure of the flow phenomena, and flame stabilization is fundamental. To improve each element thus requires a better understanding of phenomena related to the type of flow and those relating to distributions of temperature in the flame (Knaus et al. 2005; Mishra et al. 2006; J. Li 2009).Temperature flames measurement fall into intrusive and non-intrusive techniques. The intrusive methods generally use measurement probes, such as thermocouples or pyrometers. These should have very small dimensions in order to minimize the influence on the measured values (Heitor and Moreira 1993). The non-intrusive techniques are generally optical methods, such as the CARS technique: Coherent Anti-Stokes Raman Spectroscopy (Vestinet al. 2008), holographic interferometry (Xiao et al. 2000; Zhang et al. 2007) and Rayleigh Scattering (Boukhlafa et al. 1988; Franket al. 2009). These are based on the use of laser radiation which does not disrupt the flow. However, the use of these techniques represents some disadvantages such as the relatively low spatial and temporal resolution of the CARS method or the significant cost.

In our study, the measurement technique by thermocouple B type named Fine Wire Compensed Thermometry (FWCT) has been used. It presents the benefits of good spatial and temporal resolutions while being relatively simple to use. This technique is very sensitive to the conditions of temperature and flow velocity. These conditions of temperature, velocity and chemical composition of the flow can affect the physical characteristics of thermocouple materials hence the measurements quality.

\section{EXPERIMENTAL SET UP}

\subsection{Experimental Device}

The used experimental device consists of turbulent burner where the premixing to methane/air is convected with a mean velocity of $6 \mathrm{~m} / \mathrm{s}$. The Reynolds numbers obtained in our experimental setup are still below 10000 . The burner includes a seeding system of methane which is injected axially into a pre-mixer with air. A laminarisation system, and a set of grids allows the control of the turbulence level.

Spaces between the holes give rise to wakes which mix downstream from the grid. In the absence of turbulence grid, the outgoing flow of the burner on a level of very weak turbulence (lower than $1 \%$ ). The burner exit section has a length of $180 \mathrm{~mm}$ width of $6 \mathrm{~mm}$ (Boulahlib et al. 2004). Interchangeable grid turbulence can generate various conditions of homogeneous and isotropic turbulence: laminar case and turbulence intensity of $6 \%, 6.5 \%$ and $7.5 \%$ (Table 1). Thus, the flames produced with various conditions of equivalence ratio $\varphi(0.6 \div 1.3)$ and turbulence is propagated in the combustion chamber under atmospheric pressure (Fig. 1).

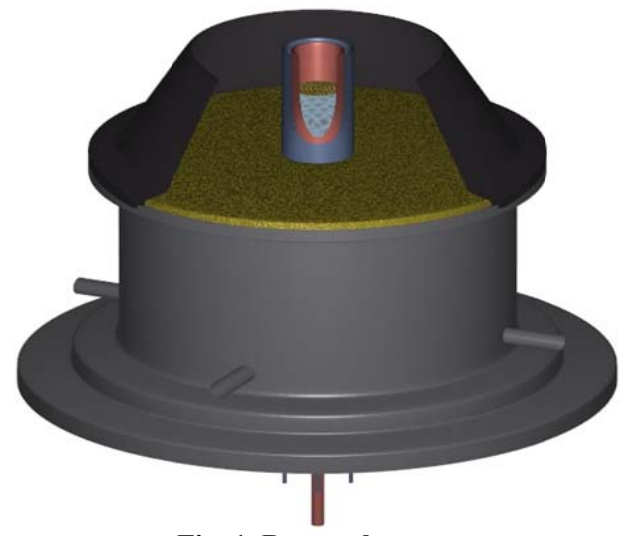

Fig. 1. Bunsen burner.

Table 1 Turbulence conditions

\begin{tabular}{|l|l|l|l|l|l|}
\hline Grid & $\begin{array}{l}M \\
(\mathrm{~mm})\end{array}$ & $\begin{array}{l}d_{h} \\
(\mathrm{~mm})\end{array}$ & $\begin{array}{l}\sigma(\% \\
)\end{array}$ & $\mathrm{C}_{\mathrm{D}}$ & $\begin{array}{l}\mathrm{u}^{\prime} / \mathrm{U} \\
(\%)\end{array}$ \\
\hline $\mathrm{P}$ & 2.40 & 2 & 0.38 & 37.5 & 7.4 \\
\hline $\mathrm{M}$ & 3.53 & 3 & 0.34 & 26.5 & 6.5 \\
\hline $\mathrm{G}$ & 4.54 & 4 & 0.30 & 18.4 & 6.0 \\
\hline
\end{tabular}

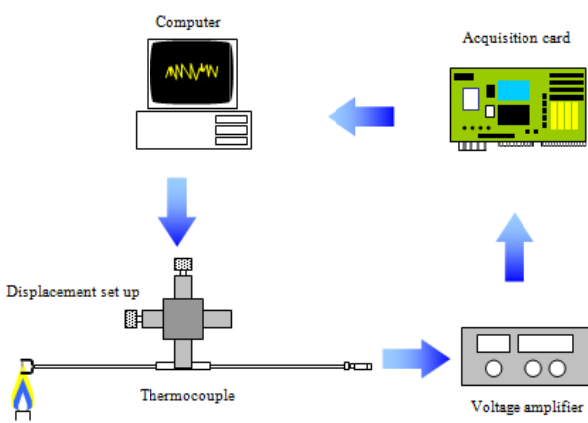

Fig. 2. Experimental set up.

The characteristics of the turbulent flow like velocities were determined by PIV (Particle Image Velocimetry).Table1, summarizes the turbulence characteristics for the various flames displayed. The $\mathrm{u}^{\prime} / \mathrm{S}_{\mathrm{L}}$ (where $\mathrm{u}^{\prime}$ is radial velocity fluctuation and $\mathrm{S}_{\mathrm{L}}$ laminar flame velocity) values vary from 2.46 to 4.04. The studied flames are located in the flamelet regime (Boulahlib et al. 2004). When one of the thermocouple junctions is maintained at a temperature different from the others, an electromotive force in the electrical system appears due to the different nature of metals (Seebeck effect).

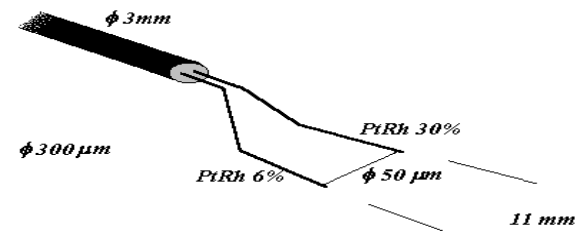

Fig. 3. Thermocouple wire used.

In our study, we use a B type thermocouple. Fig. 3 shows schematically this one. The hot weld of these 
thermocouples is made with two wires having small-diameters $(10 \div 500 \mu \mathrm{m})$ so as to increase the temporal and spatial resolutions. The wires are fixed on pins, which are made in the same alloy (Fig 3).

\subsection{Thermocouples in a Reacting Flow}

The use of thermocouples for a temporal resolution of the measurement in high temperatures requires specific treatment of these values. When the temperature of the environment is high, the loss of radiant heat from the wires becomes important. Thus, the temperature measured by the hot junction is less than the temperature of the environment. These heat losses have been estimated and discussed by many authors (Scradron and Warshawsky 1952; Kaskan 1956; Entwistle and Bradly 1961; Bradly and Matthews 1968; Paranthoën and Lecordier 1996). Their estimates by the proposed models can correct the difference between the thermocouple temperature and the realgas temperature. In addition, knowledge of the temporal resolution for the thermocouple signal is a very important parameter for fluctuating flows studies. The study presented by Lenz and Günter (1980) characterizes the temperature fluctuations up to $8 \mathrm{kHz}$ in a turbulent diffusion flame, fueled by natural gas. Neveu et al. (1994) have coupled the measurement of temperature $(2 \mathrm{kHz})$ and speed obtained simultaneously to correlate and examine the turbulent flow of a nonpremixed methane/air burner. Poireault (1997) studied a swirled burner in order to understand the influence of the swirl number on the flame stabilization. He characterized the areas of the three-dimensional flow through the modality of the probability function of the temperature signal. One can also note further investigations where the response time of the thermocouple is essential, in the methanol flames (Weckmann and Strong 1996), in the deflagration of solid combustion (Lu et al. 1995), or during the characterization of detonations (Rickman and Barker 1997), in studied of the thermal and dynamic fields in a domestic model boiler (Larass 2000). For obtaining a temporal resolution which is sufficient to study different flow types, several options were selected in the literature. Howard et al. (1995) used a thermocouple with a fine wire diameter small enough $(\mathrm{d}=51 \mu \mathrm{m})$ to respond to temperature fluctuations in the flow. But to capture fluctuations beyond a few tens of Hertz, the thermocouple signal must be compensated for its inertia. Such compensation can be done 'in situ' by using an electronic compensator (Ballantyne and Moss 1977; Lockwood and Moneib 1981; Yoshida et al 1997), or by two identical thermocouples with two different diameters (Vachon et al. 1986; Mc Quay and Cannon 1996; Tagawa and Ohta 1997).

It is also possible to apply digital offsetting by postprocessing (Hilaire et al. 1991; Neveu 1994 and Larass 2000). The FWCT (Fine Wire Compensed Thermocouple) technique, was chosen for this study. It has the advantages of allowing a better signal processing and the use of a single thermocouple. The use of this technique requires an accurate knowledge of heat transfer between the thermocouple and the flow, the physical characteristics of the materials of the probe used and its geometrical dimensions.

\subsection{Heat Exchange}

The theoretical study of heat transfer between a thermocouple and its environment was carried out by Scradron et al. (1952). The study takes into account signal compensation for the radiation losses and quantifying the response time of the thermocouple. There are also recent studies that discuss the theoretical approach of this method and show its advantages and its limit (Nina et al. 1985; Sbaibi et al. 1989; Neveu et al. 1994). The energy balance performed on a unit length $\mathrm{dx}$ of the thermocouple in a flow (Fig 3) is presented below. It is valid for an ideal welding of the fine wire of the thermocouple. This is considered as a cylindrical body.

Accumulation (Acc) $=$ Convection (A) + Conduction $(\mathrm{B})+$ radiation $(\mathrm{C})+$ Catalysis (D)

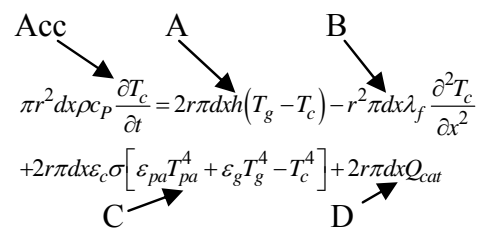

\section{Convection (A):}

The A term of energy balance characterizes the convection heat transfer between the thermocouple and its environment. It is assumed in all the measures that the flow temperature is constant over the entire wire length. This assumption is valid only in the two-dimensional flow and by placing the thermocouple wire in the axis of zero temperature gradient.

\section{Conduction Exchange (B):}

The temperature uniformity of the environment around the wire does not ensure on its own the temperature homogeneity along the wire.At high temperature, there is always a gradient between the wire and pins bearing the fine wire, as a result of radiation losses, which vary according the diameter. Bradley et al. (1986) have determined the length of wire for which the exchange between the conductive wire and its support no longer influences the measuring point $(1=200 \mathrm{~d})$. It can therefore be assumed that B part of the heat balance is negligible compared to the other terms.

\section{Radiative exchange (C):}

The $\mathrm{C}$ term represents the radiative exchange between the thermocouple and the environment, therefore gas flow and the burner walls. The methane/air flames producing mainly $\mathrm{CO}_{2}, \mathrm{H}_{2} \mathrm{O}$ and nitrogen. The combustion products emissivity of such a flame can be neglected because it is very low $\left(\varepsilon_{g} \sim 0.03\right.$ for a stoichiometric mixtureand an open burner (Hottel and Sarofim1967).

Inflow of heat via catalytic effect (D):

The thermocouples B type are composed of 
materials such as platinum or rhodium, which are oxidation catalysts. In reacting flows in the presence of $\mathrm{CH}_{4}$ or $\mathrm{CO}$, surface reactions occur on the thermocouple wire and can influence the
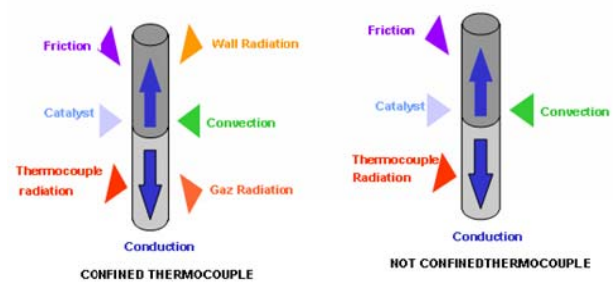

Fig. 3. Heat transfer between the thermocouple and its environment.

measured temperature (Kent 1970, Burton et al. 1992). Therefore, this coating has been developed. Assuming a smooth functioning of the coating, the catalyst term (D) can be neglected. Taking into account the above considerations gives the simplified balance:

$$
\begin{aligned}
& r^{2} d x \rho c_{P} \frac{\partial T_{c}}{\partial t}=2 r d x h\left(T_{g}(t)-T_{c}(t)\right)+ \\
& 2 r d x \varepsilon_{c} \sigma\left[T_{c}(t)^{4}-\varepsilon_{p a} T_{p a}^{4}\right]
\end{aligned}
$$

The balance can be written using the Nusselt number and wire diameter $\mathrm{d}=2 \mathrm{r}$.

$\frac{\partial T_{c}}{\partial t}=\frac{4 N u \lambda_{g}}{d^{2} \rho c_{p}}\left(T_{g}(t)-T_{c}(t)\right)+\frac{\varepsilon_{c}\left(T_{c}\right) \sigma S}{\rho c_{p} V}\left(T_{c}(t)^{4}-\varepsilon_{p a} T_{p a}^{4}\right)$

Many authors have estimated the Nusselt number by semi-empirical or theoretical correlations, but with a small diameter wire, the Reynolds number is small $(\operatorname{Re}<1)$ and only two correlations are mainly used:

- Kramers (1946) correlation is valid for a Reynolds number between 0.01 and 10000 .

$N u=0,24 \operatorname{Pr}^{0,20}+0,57 \operatorname{Pr}^{0,33} \cdot \operatorname{Re}^{0,50}$

- Nusselt correlation proposed by Collis and Williams (1959) is given for two regimes of Reynolds number.

For $0.02<\operatorname{Re}<44$

$N u\left(\frac{T}{T_{g}}\right)^{-0,17}=0,24+0,56 \cdot \mathrm{Re}^{0,45}$

and for $44<\operatorname{Re}<140$

$N u\left(\frac{T}{T_{g}}\right)^{-0,17}=0,0+0,48 \mathrm{Re}^{0,51}$

Kramers correlation has been used by Bradley and Matthews (1968); Dupont et al. (1984); Nina and Pita (1985), to describe the heat transfer around a thermocouple (Pr is Prandtl number). Studies of Bradbury and Castro (1972); Lecordier et al. (1981) on the effect of conduction influence on the transfer function of the thermocouple wires have shown a good agreement between the correlation given by Collis and Williams (1959) and experimental results. A study presented by Kurdyumov and Fernàndez (1998) reviewed Nusselt number correlations and proposed a solution particularly suited to small Reynolds numbers. This correlation is also in good agreement with that of Collis and Williams. So, we will use the first part of the correlation of Collis and Williams (1959) (Eq. 5).

\subsection{Digital Compensation}

The compensation is needed for two reasons. The first relates to the temperature displayed by a thermocouple, which is not necessarily the environment gas temperature as a result of radiation losses from high temperature thermocouples. For the gas temperature, it is necessary to estimate and correct those losses. The second reason relates to the thermocouple response time, which is limited by the two wires inertia. Knowing the response time characteristic of the thermocouple, ie time constants $\tau$, we can reconstruct the original signal temperature. The method, which takes into account the convective and radiative effects, is directly extracted from the energy balance. It is determined by introducing the gas temperature and the convective time constant. If we keep only equation (1) only the convective term, we obtain equation (9). The time constant $\tau_{\mathrm{cv}}$ is defined by Equation 8 (Scadron and Warshawsky 1952; Ballantyne and Moss 1977). The determination of the time constant for improving the temperature measurement method is an important aspect that has been mentioned in several studies (Neveu et al. 1994; Larass et al. 1995; Larass2000).

$\frac{\partial T_{C}}{\partial t}=\frac{4 N u \lambda_{g}}{d^{2} \rho c_{p}}\left(T_{g}(t)-T_{c}(t)\right)$

where:

$\tau_{c V}=\frac{d^{2} \rho c_{p}}{4 N u \lambda_{g}}$

$T_{g}=T_{c}+\tau_{c v}\left(\frac{\partial T_{c}}{\partial t}-\frac{\varepsilon_{c} \varepsilon_{p a}}{1-\left(1-\varepsilon_{c}\right) \cdot\left(1-\varepsilon_{p a}\right)} \cdot \frac{4 \sigma\left(T_{c}^{4}-T_{p a}^{4}\right)}{d \rho c_{p}}\right)$

The equation obtained (9) allows us to have simultaneously offsetting losses by radiation and inertia. The compensation of thermocouple inertia requires an iterative process.

\subsection{Thermocouples B Type}

The main characteristics of thermocouples are defined by the alloy choice. A summary of existing combinations and an interpretation of their characteristics were provided by Kinze (1973). This alloy is made according the nature of the gaseous medium and its temperature. For combustion studies, we therefore used type B thermocouples.

The thermocouple B type (Pt30\%-Rh Pt6\%) is used in the temperature range from 700 to $2000 \mathrm{~K}$, where it has good signal amplitude (about $9 \mu \mathrm{V} / \mathrm{K}$ ).

The thermocouples based on Pt-Rh (platinum/rhodium) alloys provide a good stability of their signals (Kinzie 1973, Heitor and Moreira 1993). A diameter of $50 \mu \mathrm{m}$ was chosen to be a good compromise between a low-inertia 
thermocouple and a sufficient mechanical strength.

\subsection{Stability of the Response Signal of Thermocouples}

The use of thermocouples in a reactive flow at high temperature can alter their physical characteristics. The phenomenon has been studied by Ahmed et al. (1987); Hayhurst and Kittelson (1977) where from $1000 \mathrm{~K}$ Iridium oxide forms and vaporizes. This vaporization alters the composition of the wire alloy $\mathrm{Ir} 4 \mathrm{O} \% \mathrm{Rh}$, which is enriched in Rhodium, and consequently the electromotive force of the thermocouple is changed. The signal from a thermocouple Iradium-Rhodium ( $\operatorname{Ir} / \mathrm{Ir} 40 \% \mathrm{Rh})$ in evaporation case will first slightly increase and then decrease when the composition of the alloy exceeds $50 \%$. The presence of silicon derivatives $(\mathrm{SiO} 2$ from refractory, silicone oil) in the environment of a B thermocouple may cause its poisoning. From a temperature above $1400 \mathrm{~K}$, platinum silicate can form in a B thermocouple and change its characteristics (Bennett 1961). In this case, the best way to obtain reliable results is to protect the thermocouple with a coating. To minimize the effects due to thermal and mechanical stresses, some authors apply a process which consists in annealing the thermocouple at high temperatures (Ahmed et al.1987). Using this process signal stability thermocouple can be improved.

\subsection{Correction Radiation Losses}

At high temperature, the value measured by the thermocouple does not correspond to the environment in which it is placed. This difference is mainly due to radiation losses from the thermocouple.

The temperature of the flow can therefore be estimated if all variables are known with sufficient precision. The theoretical values for uncoated thermocouples were calculated from equations proposed by Entwistle and Bradly 1961; Hayhurst and Kittelson 1977). The emissivity of thermocouple metals depends on their electrical resistivity " $r$ ", and the temperature " $\mathrm{T}$ ".

Bradley and Entwistle:

$$
\begin{aligned}
\mathrm{e} & =0.751 \cdot\left(\mathrm{T} \cdot \mathrm{R}_{\mathrm{e}}\right)^{1 / 2}-0.632 \cdot \mathrm{T} \cdot \mathrm{R}_{\mathrm{e}} \\
& +0.670 \cdot\left(\mathrm{T} \cdot \mathrm{R}_{\mathrm{e}}\right)^{1 / 2}-0.670 \cdot\left(\mathrm{T} \cdot \mathrm{R}_{\mathrm{e}}\right)^{2}
\end{aligned}
$$

Hayhurst and Kittelson:

$$
\mathrm{e}=0.751 .\left(\mathrm{T} \cdot \mathrm{R}_{\mathrm{e}}\right)^{1 / 2}-0.396 . \mathrm{T} \cdot \mathrm{R}_{\mathrm{e}}
$$

The results obtained from these two correlations were presented by Larass (2000). There is only a slight difference between the two equations for $\mathrm{B}$ type thermocouple. A comparison of calculation models of emissivity of B type thermocouple has been made by Larass (2000).

\subsection{Sampling}

Temperature fluctuations that should be followed by the thermocouple in a flame are in the order of hundred $\mathrm{Hz}$ up to $1 \mathrm{kHz}$. To avoid bias in the experimental signal acquisition, the sampling frequency must be at least four times greater than the expected cut-off frequency (in our case $1 \mathrm{kHz}$ ) of measured signals. The sampling frequency has been chosen equal to $10 \mathrm{kHz}$ and the acquisition duration was 5 seconds so as to correctly average the signal by integrating over a sufficiently long period. This helps to find a compromise between quality measurement (50000 points) and good management of computer memories. The signals have been filtered and a cutoff frequency of $300 \mathrm{~Hz}$.

\subsection{Experimental Devices}

The experimental device used consists of a turbulent Bunsen burner where $\mathrm{CH}_{4} / \mathrm{air}$ (G20) is convected with an average velocity of $6 \mathrm{~m} / \mathrm{s}$ and an equivalence ratio in range $\varphi=0,6 \div 1,3$ (Boulahlib et al. 2008). The burner diameter is $30 \mathrm{~mm}$. The reacting flow is surrounded by an annular flow. The positioning of thermocouples in the flame was carried out through a system of movement of two axes Charly Robot (Fig 2). The movement precision is in order of $0.1 \mathrm{~mm}$ following (x), and $1 \mathrm{~mm}$ in the height flame direction (y). The uncertainty caused by the displacement table can be considered negligible. However, the expansion and contraction of the junction and pins in the hot and cold zones of the flow can cause deformation of the probe. This can vary the position of the junction. The importance of this variation according of flow and temperature and can therefore vary at each measuring point. Temperature measurements were made in each case according to a grid divided into four zones. The measures are carried out over a width ranging from $x=40$ to $54 \mathrm{~mm}$ with a step of $0.1 \mathrm{~mm}$.

\section{RESULTS}

The presentation of two-dimensional fields of the average temperature (Fig 4a, b and c) is very useful for the structures visualization of the reaction and cold zones in a flame. The analysis of these fields facilitates understanding of the flow thermal structure using a comparison between the different cases studied. The overall study of two-dimensional representations shows that the thermal structures are almost similar. The use of different scales of turbulence does not prima facie significant difference in the structure of thermal fields means; however, a closer examination will show a bit further other aspects in the analysis of radial, longitudinal evolutions, the heights and flames thicknesses. Temperature fields present a quasiparabolic form whose maximum is located just after the end of the internal conical part. On Fig $4 a, 4 b$ and $4 \mathrm{c}$, the different areas of the flame and the secondary flow are clearly identified. The overall structure of these flames is that of two-dimensional Bunsen type flames. The flame area represented by the isotherm at $1500{ }^{\circ} \mathrm{C}$ is at the height $\mathrm{y}=15$ $\mathrm{mm}$. The maximum width is about $54 \mathrm{~mm}$ at $\mathrm{y}=150 \mathrm{~mm}$ for the $\mathrm{G}$ grid. The combustion zone is surrounded by the air jet coflow, whose thermal structure is clearly identified. It may be noted that 
the maximum temperature zones are located on both sides of the central axis of the flame. The highest temperatures are located on the flame edges due to the mixing between the air and the reaction zone.

The maximum temperature zone is the basis for all flames, due to lack of mixing with ambient air. One characteristic of these flames is the presence of hot zones rather thin at the base, and more and more extensive progressing in height in the flame, to finally end in a thickening and cross at the end. This slight difference is mainly due to large fluctuations in temperature on the upper parts of the flame by induced flames frequencies which create thermal dilution on average measurements. Temperature gradients are very high. Note that these profiles are progressively widened as one moves from the $P$ to the $G$ grid which corresponds to an increase of the flame surface due to a decrease in the turbulence intensity. The maximum temperature reached by the combustion flame is differentiated by the turbulence effect. The M0.6 flame represents the lower combustion temperature (Fig 4).

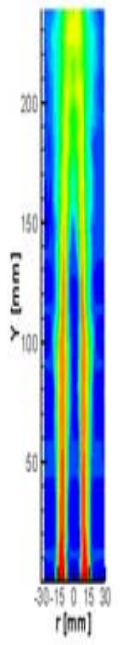

(a)

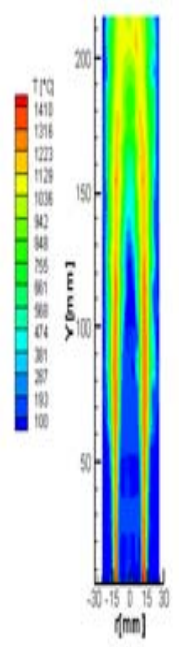

(b)

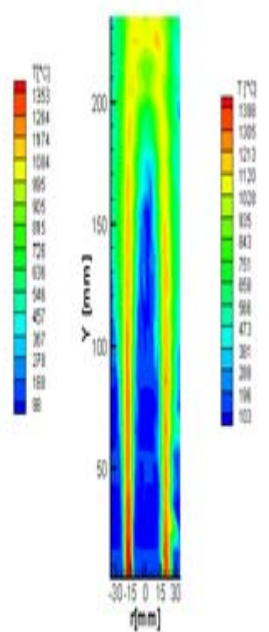

(c)
Fig. 4. Two-Dimensional Temperature for P0.6 (a); M0.6 (b) and G0.6 (c) flames.

To analyze the results more precisely, we present the average temperature results in the profiles form and varying heights. Flames with an equivalence ratio $\Phi=0.6$ (Fig 5a, 5b, 5c, 5d and 6) for the three turbulence grids and varying heights will be compared. The evolution of radial profiles at $\mathrm{y}=5$ $\mathrm{mm}$, is presented for the three grids (Fig 5a).

Note that the temperature gradient in the flame inside is similar for all 4 cases. It may be noted that the $\mathrm{P}$ grid is the one with the largest maximum temperature, and the $\mathrm{G}$ grid the thicker profile. The measured temperatures are of the same size, with a different maximum temperature which is more important for the $\mathrm{P}, \mathrm{M}$ and finally $\mathrm{G}$ grid. The maximum temperature also has two peaks on either side of the central axis $\left(\mathrm{T}=1500^{\circ} \mathrm{C}\right)$, but they are located further from the axis $(\mathrm{r}=-12 \mathrm{~mm})$.

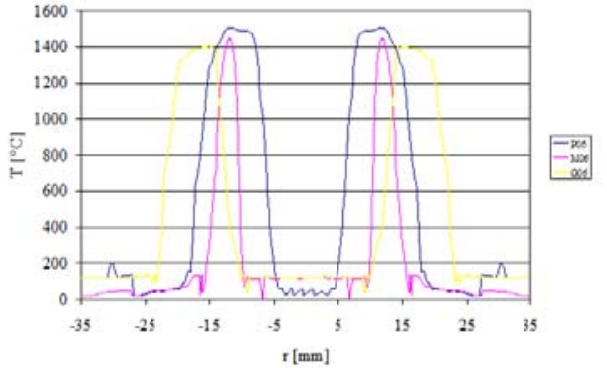

(a)

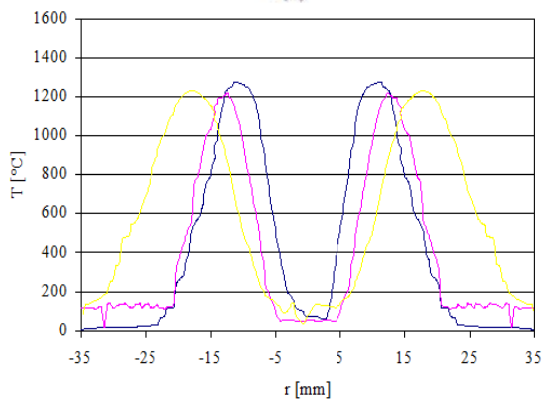

(b)

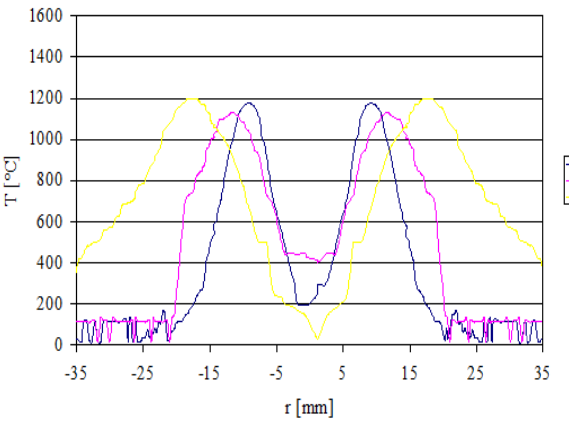

(c)

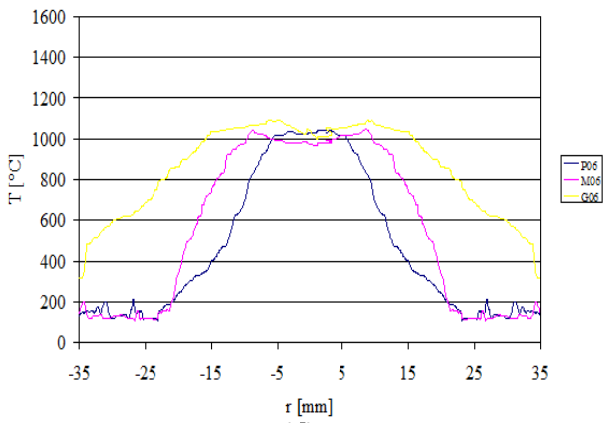

(d)

Fig. 5. Average temperatures in radial direction, for different grids, equivalence ratio $\Phi=0,6$ and different heights $(a=5 \mathrm{~mm}, b=100 \mathrm{~mm}, c=155 \mathrm{~mm}$ and $d=240 \mathrm{~mm}$ ).

The same trends were observed for different height (Figs. 5.a, b, c and 6), but the temperature gradients inside and outside are somewhat less important.

In Fig 7, we can see that the fluctuations for all cases are well ordered; we observe that in the region between 0 and $\mathrm{y}=150 \mathrm{~mm}$, they are lower than in the reaction region. Then, we can see that these fluctuations become more important when one progresses in height. 


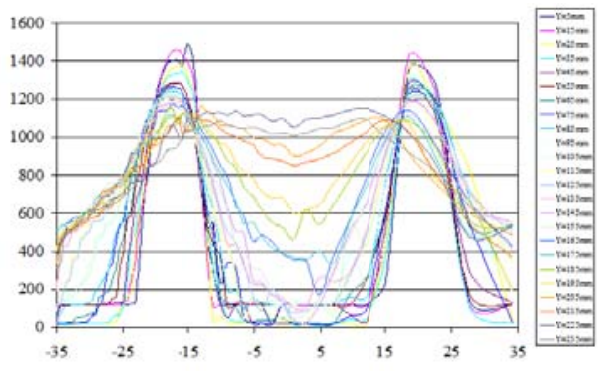

Fig. 6. Average temperature in the radial direction and of varying heights for the $G$ Grid and an equivalence ratio $\Phi=0,6$.

These fluctuations which are important in the reaction zone and variable as a function of height explain the differences in temperature observed in Fig. 5a.

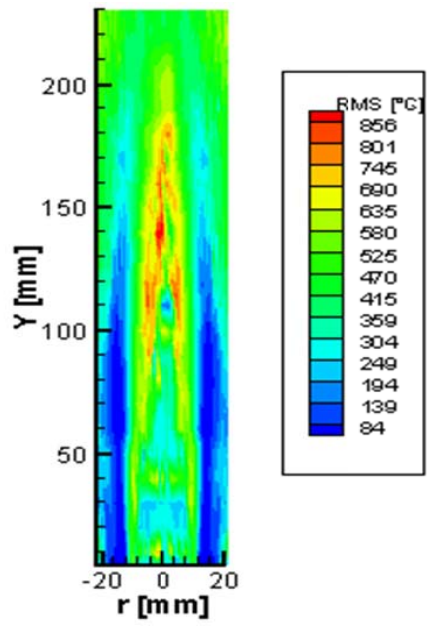

Fig. 7. Two-dimensional RMS Temperature Field.

The temperature fluctuations in the flow are represented by standard deviation of compensed temperature (Fig. 8). The digital compensation presents very consistent results. In fig 8 , it is clear that digital compensation of a signal temperature tends to accentuate its typical deviation, the error made on the average temperature is more important from $1200{ }^{\circ} \mathrm{C}$ onwards.

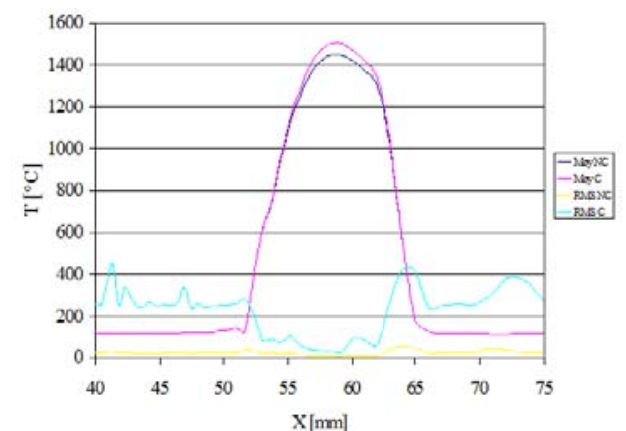

Fig. 8. Temperature and RMS for P0.6 flame and $Y=05 \mathrm{~mm}(C$; compensed and N.C not compensed).

It would, therefore, be interesting to interpret the spatial structures characteristics fluctuations according of their operating conditions: These fluctuations have low values in fresh gases areas: on average, they are between 1 and $4{ }^{\circ} \mathrm{C}$ on both sides of the symmetry axis of burner, therefore about $0.2 \%$ lower than the hot gases temperature. In interaction areas of fresh gas with the combustion zone (corresponding to the two peaks characterizing the reaction zone), we observe the highest fluctuations. Great fluctuations have been observed close to the flame front; in fact, the standard deviations are especially high in the flame front region due to the thermal and aerodynamic disturbances caused by the chemical reaction. In the jet center, the standard deviations are low. Measurements validation made by the FWCT technique requires a comparison with optical measurements (Rayleigh Scattering) methods. Medium quantities obtained by this method are easily comparable to those determined by the optical technique based on Rayleigh scattering. Such a comparison is more difficult for the fluctuating quantities because the reference technique, based on a different physical principle, also includes several sources of error. We present in Fig. 9 a comparison between the average temperature deduced from the measurements by thermocouples and by Rayleigh Scattering, obtained in a turbulent premixed methane-air flame whose $\varphi=0.6$ and Reynolds number of ejection is 10000 .

The results of Rayleigh Scattering are those of Boukhalfa et al. (1988), whose experimental conditions are almost identical to our results. It is noted that the two curves have generally the same form. When one looks more closely to these curves, we can see that from $\mathrm{Y} / \mathrm{R}=0.8$, the "Rayleigh" temperature is systematically overvalued compared to that provided by the "thermocouple".

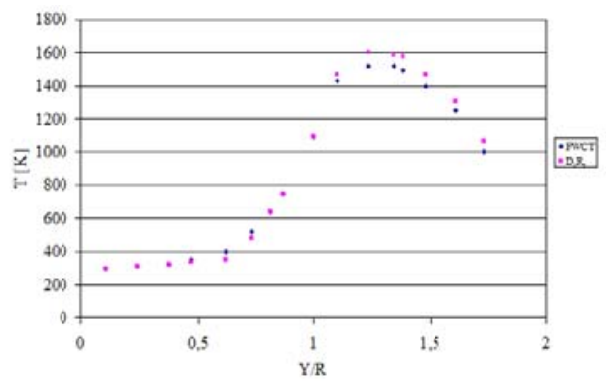

Fig. 9. Comparison between FWCT and Rayleigh scattering temperature at $Y / D=2,5$.

The decrease of the average cross section in the burned gases, as well as errors caused by fluctuations can contribute to this outcome. The match between Rayleigh scattering temperature and the thermocouple temperature is very satisfactory, and the maximum deviations observed are between 5 and $10 \%$. Similar comparisons have been carried out by Namer et al. (1980); Chandran et al. (1985) and Boukhalfa et al. (1988). They have shown that the temperature values in a methane-air premixed flame on Bunsen burner without correction for radiation losses or the cross section show either overestimates or underestimates of the temperature. 
These differences depend on the fuel, equivalence ratio and vary between $100 \mathrm{~K}$ and $250 \mathrm{~K}$.

This slight difference is mainly due to large temperature fluctuations on the upper parts of the flame-induced frequency of flames, which create thermal dilution on the mean measurements.

Table 3 Comparison of Rate of Heat Release in Different Flames

\begin{tabular}{|c|c|c|}
\hline Flame & $\tau_{\text {ad. }}$ & $\tau_{\text {exp. }}$ \\
\hline P0.6 & 4.69 & 4.72 \\
\hline P0.7 & 5.2 & 5.10 \\
\hline P0.8 & 5.61 & 5.12 \\
\hline M1.0 & 6.38 & 5.40 \\
\hline P1.3 & 5.81 & 5.60 \\
\hline
\end{tabular}

The calculation of the heat release rate based upon the adiabatic temperature gives a good agreement with measurements (Table 3). Such a comparison is more difficult for the fluctuating variables as the reference technique which is based on a different physical principle, also has several error sources. The profiles of average temperature can also allow the calculation of the heat release in different flames, from the maximum values of the ratio $\operatorname{Tr} / \mathrm{Tp}$. Table 3 shows the comparison between the experimental heat release and those corresponding to the adiabatic flame temperature. The experimental values of $\tau=\left(\mathrm{T}_{\mathrm{p}}-\mathrm{T}_{\mathrm{r}} / \mathrm{T}_{\mathrm{r}}\right)$, for each flame, taken equal to the average calculated from several profile. The study of the temperature evolution on the burner axis informs us about the participation of this jet in mixing and combustion. The longitudinal profiles of temperature measured at the burner center are presented together with the temperature obtained by the thermocouple located at $\mathrm{r}=0 \mathrm{~mm}$ (Fig 10).

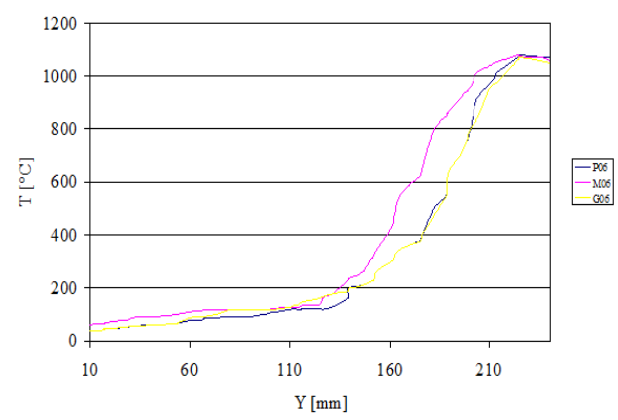

Fig. 10. Average temperatures in the longitudinal direction of the burner Axis $(r=0)$ for different grids (P, M and $G$ ), with $\Phi=0.6$.

It may note the existence of four areas. The first area characterized by a tray and a very slow evolution of temperature, and which corresponds to fresh gas, is followed by a second preheating zone. Followed by a region where the temperature first increases abruptly during the passage through the flame front, then it increases more slowly heated by a post-combustion, then a slow decrease in temperature is observed, corresponding to the mixing zone between burned gases and the outside air. The 3 grids show similar trends with different gradients. The longitudinal iso-temperatures measured in the axial direction, represent a zoom on a flame portion. They are presented in Fig 11. At the burner base, the minimum temperature representing the fresh gas is around the coordinates $\mathrm{X}=53 \mathrm{~mm}$, then advancing, the spacing of isotemperature is more regular, and from $1000^{\circ} \mathrm{C}$, it becomes more important.

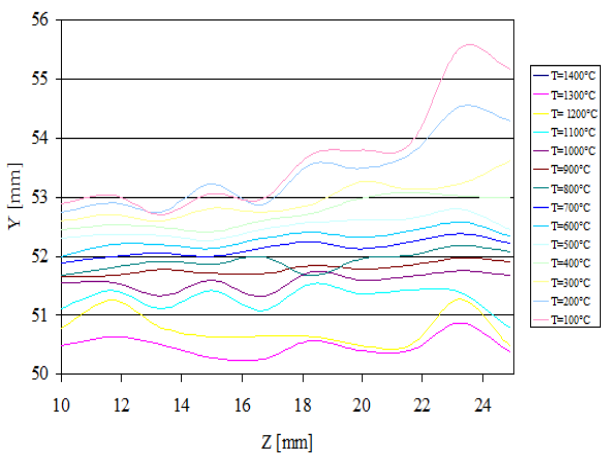

Fig. 11. Iso-temperature versus to the axial direction and for different heights for $P=0.6$.

The maximum temperature is reached directly above and near the burner wall. The highest temperature lines that represent the flame front position are located near the edge. Advancing in the "Y" direction, we remark a development and a progressive thickening of the iso-temperature fields, regular spacing between 500 and $900^{\circ} \mathrm{C}$, and much bigger steps between both 100 and $500{ }^{\circ} \mathrm{C}$ on one side and 900 and $1300^{\circ} \mathrm{C}$ from each other, and which correspond to the panache developing. The longitudinal profiles of the maximum temperature according to the equivalence ratio and the same turbulence grid are shown in Fig 12.This is used to locate the maximum temperature obtained as a function of equivalence ratio. This presentation shows that for these flames, the lowest temperatures correspond to an equivalence ratio of 0.6 and higher than 1.1 .

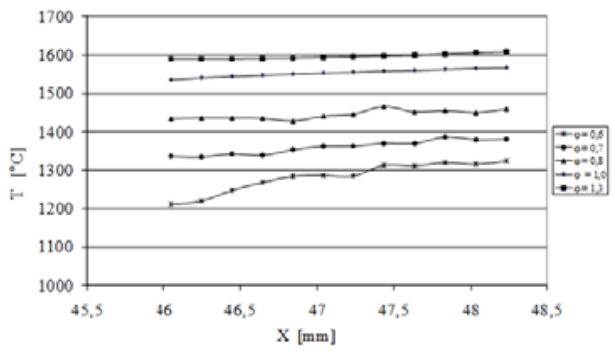

Fig. 12. Equivalence ratio effect on the maximum temperatures $(\mathrm{Y}=\mathbf{2 0 0} \mathbf{\mathrm { mm }})$.

Figure 13-16 represent the evolution of the variable progress $<\mathrm{c}>$ for all flames. The progress variable has been obtained from the average temperature fields represented by the expression (12) (Peters 2000). In Fig 13, it appears that these profiles are on average from the same internal height.

$\mathrm{c}=\frac{\mathrm{T}-\mathrm{T}_{\min }}{\mathrm{T}_{\max }-\mathrm{T}_{\min }}$ 
However, they stand out due to the differences in heat release rate. The slopes increase with height. Fig 14 shows the iso $\langle\mathrm{c}\rangle$, calculated from the thermal field in a flame portion. Starting from the burner basis, the results clearly demonstrate a thickening of the flame front corresponding to an increase of the apparent surface of the turbulent flame.

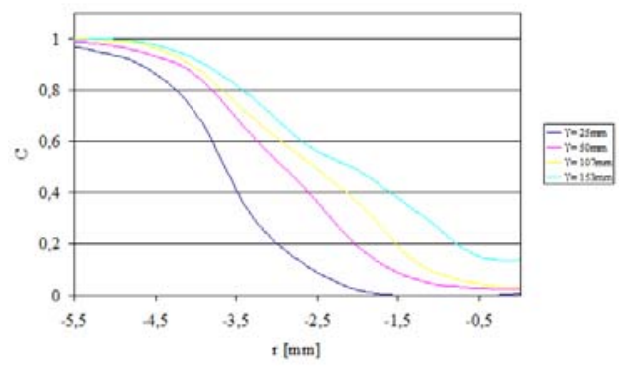

Fig. 13. Variable progress $<\mathrm{c}>$, for $\mathrm{P0.6}$ flame

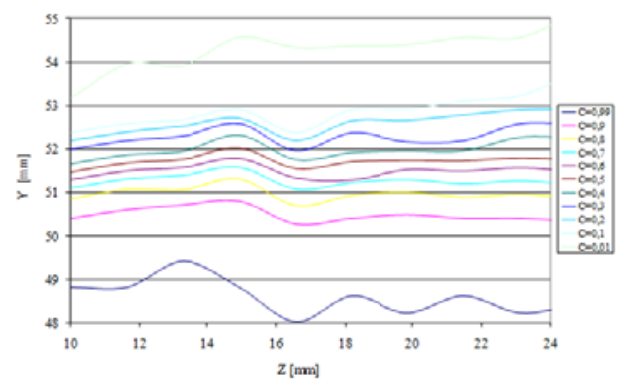

Fig. 14. Iso- $<\mathrm{c}>$ evolution for $\mathbf{G} 0,6$ flame.

Figure 15 shows that the profile of $<\mathrm{c}>$, is an evolution indicator of the thermal field and therefore the reaction. The influence of the height in the flame is very clear. $<\mathrm{c}>=0.05$ determines the start and $\langle\mathrm{c}\rangle=0.99$ the end of the combustion process.

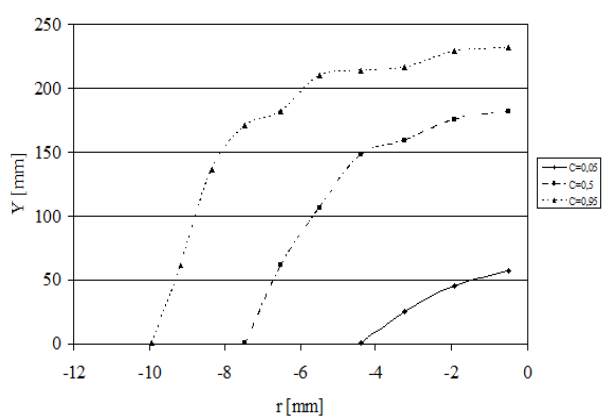

Fig. 15. Iso $<c>$ Evolution for $P 0,6$ flame.

Figure 13-16 show that the profile $\langle\mathrm{c}\rangle$ is sensitive length scale. Profiles corresponding to the grids generating small scale turbulence reveal an internal height greater than that relative to the grids generating large scale turbulence. Y. C Chen et al. (1996) in his experimental work, ROS Prassad et al. (1999) and Lipatnikov and Chomiak (2002) in their numerical predictions happen to have comparable trends of the progress variable $<\mathrm{c}>$.

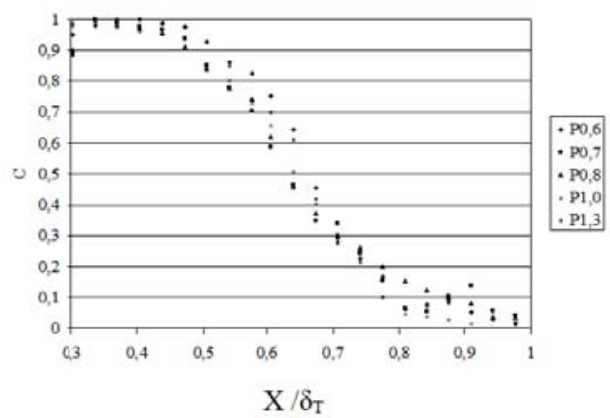

Fig. 16. Profiles Standardization of the Progress Variable $<\mathrm{c}>$ at $\mathrm{Y} / \mathrm{D}=\mathbf{0 . 3 3}$

The turbulent flame thickness $\left(\delta_{\mathrm{T}}\right)$ is used to normalize the progress variable $<\mathrm{c}>$. Fig 13 shows the variable progress profiles deduced from the average temperature for flames studies. Standardization by the flame thickness makes geometrically similar profiles of the variable $<\mathrm{c}>$ which overlap quite well, at different heights and for different flames. These normalized developments thus confirm that the scalar average structure of premixed turbulent flames studied here may be made using the above universal standardization. These results confirm the work on the conical and V flames (Namazian et al. 1986; Cheng and Shepherd 1986; Anan and Pope 1986; Boukhalfa et al. 1988; Deschamps 1990; Bourguignon 1997; Lipatnikov and Chomiak 2005).

\section{CONCLUSION}

An experimental procedure with post processing was developed to determine the thermal field in premixed turbulent flames. Using the Fine Wire Compensated Thermometry (FCWT) technique, temperature profile measurements were performed on turbulent premixed flame $\mathrm{CH}_{4}$-air with equivalence ratio $\varphi=0.6-1.3$. The Fine Wire Compensated Thermometry (FWCT) is characterized by a good measurement precision.

The application of numerical compensation in post treatments allows the correction of thermocouple inertia and the radiation losses at high temperatures.

The digital compensation technique used in this study consists of a post-treatment. Even if the time constant is well known for temperatures where the radiation is negligible, it has never been well studied at high temperatures. The method, which takes into account the convective and radiative effects, is directly extracted from the energy balance. The addition of catalytic effect in the energy balance takes good results. The characteristic results are: the temperature fluctuations are quite low values in the area of cold gas; on average, there are between 1 and $4{ }^{\circ} \mathrm{C}$ on both sides of the symmetry axis of the burner, so lower than about $0.2 \%$ of the hot gas temperature. The FCWT has very acceptable results, and comes to correct the defects of the temperature measurement in the flames by using fine wire, the introduction of digital compensation and catalytic 
protection while remaining very affordable in terms of costs compared to Rayleigh scattering. The FWCT has very acceptable results, and comes to correct the defects of the temperature measurement in the flames. The introduction of digital compensation and catalytic protection while remaining very affordable in terms of costs compared to Rayleigh scattering. The comparison between FCWT and Rayleigh scattering results shows a good agreement.

\section{REFERENCES}

Ahmed S., E. F. Germain, K. Daryabeigi, D.W. Alderfer and R.E. Wright (1987).A preliminary study of factors affecting the calibration stability of the Iridium versus Iridium $40 \%$ Rhodium thermocouple. NASA Technical Memorandum 89086.

Al-Abdeli, Y. M. and Assaad R. Masri (2015). Review of laboratory swirl burners and experiments for model validation. Experimental Thermal and Fluid Science 69, 178-196.

Bakhshan, Y. and A. H. Shadaei (2013). QuasiDimensional Modeling of a CNG Fueled HCCI Engine Combustion Using Detailed Chemical Kinetic. Journal of Applied Fluid Mechanics 6(2), 239-247.

Ballantyne, A. and J.B. Moss (1977). Fine wire thermocouple measurements of fluctuating temperature.Combustion Science and Technology 17, 63-72.

Bennett H. (1961). Platinium Metals Revue 5(4), pp.132, 1961

Boukhalfa, A. and I. Gokalp (1988).Influence of the Damkôhler number on the average thikness of conical turbulent premixed methane/air flames.Combustion and Flame, 73, 75-87.

Boulahlib, M. S., B. Renou, A. Boukhalfa and Z. Nemouchi (2004).Etude expérimentale de l'influence de la richesse et de la turbulence sur une flamme de prémélange turbulente $\mathrm{CH}_{4}$-air dans un brûleur Bunsen par Tomographie Laser.SCIENCES ET TECHNOLOGIE, série B Université Mentouri de Constantine 22, 67-78.

Bradbury, L. J. S. and I. P. Castro (1972) Somecomments on heat-transferlaws for fine wires. Journal of Fluid Mechanics 51(3), 487-495.

Bradly, D. and A. G. Entwistle (1961).Determination of the emissivity, for total radiation, of small diameter platinum $10 \%$ rhodium wires in the temperature rage $600-1450{ }^{\circ} \mathrm{C}$. British Journal of Applied Physics 12, 708-711.

Bradly, D. and K. J. Matthews (1968).Measurement of high gas temperatures with wire thermocouple. Mechanical Engineering Science 10 (4).
Buchlin, J. M. (2011). Convective heat transfer in impinging Gas-Jet arrangements. Journal of Applied Fluid Mechanics 4(2), 137-149.

Burton, K.A., H.D. Ladouceur H.D. and J.W. Fleming (1992).An improved non catalytic coating for thermocouples. Technology 81, 141-145.

Collis, D. and M. Williams. (1959). Twodimensional convection from heated wires at low Reynolds Numbers. Journal of Fluid Mechanics 6, 357-384.

Dupont, A., P. Paranthöen, J. C. Lecordier and P. Gajan (1984).Influence of temperature on the frequency response of fine wire thermocouples over the rage $(300 \mathrm{~K}-800 \mathrm{~K})$ in airflows.Journal of Physics Engineering and Scientific Instrument 17, 808-812.

Hayhurst, A. N, and D. B. Kittelson. (1977).Heat and mass transfer considerations in the use of electrically heated thermocouples of iridium versus an iridium/rhodium alloy in atmospheric pressure flames. Combustion and Flame 28, 301-317.

Heitor, M. V. and A. L. N. Moreira (1993).Thermocouples and sample probes for combustion studies. Progress in Energy and Combustion Science 19, 259-278.

Hilaire, C., E. Filtopoulos and M. Trinité. (1991). Mesure de température dans les flammes turbulentes. Développement numérique du signal d'un thermocouple. Revue Générale de thermique 354-355, 1-8.

Hottel, H. C and A. f. Sarofim (1967).Radiativetransfer.McGraw Hill Book Company 150.New York, USA.

Kaskan W. E. (1956). The dependence of flame temperature on mass burning velocity. $6^{\text {th }}$ Symposium (International) on Combustion. The Combustion Institute, Pittsburgh, 34143.

Kent, J. H. (1970).A noncatalytic coating for platinum-rhodium Combustion and Flame 14, 279-282.

Keramiotisa,C., M. Katoufaa, G. Vourliotakisa, A. Hatziapostoloub, and M.A. Fountia (2015).Experimental investigation of a radiant porous burner performance with simulated natural gas, biogas and synthesis gas fuel blends. Fuel 158 (15), 835-842.

Kinzie, P. A. (1973). Thermocouple temperature measurement,John Wiley and Sons, New York, USA.

Knaus, D. A., S. S. Sattler and F.C. Gouldin(2005).Three-dimensional temperature gradients in premixed turbulent flamelets via crossed-plane Rayleigh imaging.Combustion and Flame, 141(3), 253-270.

Kramers, H. (1946). Heat transfer from 
M. S. Boulahlib and M. A. Boukhalfa/JAFM, Vol. 9, Special Issue 2, pp. 177-188, 2016.

spheres to flowing media. Physica XII 3, 61-80.

Krishna, B. M. and J. M. Mallikarjuna (2010). Characterization of Flow through the Intake valve of a single cylinder engine using Particle Image Velocimetry. Journal of Applied Fluid Mechanics 3(2), 23-32.

Kurdyumov, V. N. and E. Fernandez (1998). Heat transfer from a circular cylinder at low Reynolds numbers. Journal of heat Transfer 120, 72-75.

Larass, N., P. F. Miquel, A. Boukhalfa, D. Honoré, M. Perrin and Trinité M (1998).Mesures de vitesses par intercorrélation d'images de particules dans des flammes laminaires d'une chaudière domestique modèle. $6^{\text {th }} \quad$ Congrès Francophone de Vélocimètrie Laser. StLouis, France.

Lecordier, J. C., P. Petit and P. Paranthoen (1981). Influence de la conduction sur la fonction de transfert des fils froids dans les très basses fréquences: résultats expérimentaux.Letters in Heat and Mass Transfer8, 103-114.

Li, J., S. K. Chou, W. M. Yang, and Z. W. Li (2009).A numerical study on premixed microcombustion of CH4-air mixture: Effects of combustor size, geometry and boundary conditions on flame temperature.Chemical Engineering Journal150(10), 213-222.

Lockwood, F. C. and H. A. Moneib (1981).A new on line pulsing technique for response measurements. Combustion Science and Technology 26,177-181.

Lu, Y. C., G. C. Harong, M.J. Chiaverini and K. K. Kuo (1995).A method for embedding fine-wire thermocouples for solid-fuel surface temperature measurements. Combustion Science and Technology 110 (111), 563-570.

McQuay, M. Q. and S.M. Cannon (1996). Timeresolved temperature measurements in the developing region of an elliptic, jet diffusion flame at a Reynolds number of 6000 . Combustion Science and Technology 119, 1333.

Mishra,T. K., A. Datta and A. Mukhopadhyay (2006). Comparison of the structures of methane-air and propane-air partially premixed flames. Fuel 85(9), 1254-1263.

Namer, I. (1980). An experimental investigation of the interaction beetwin a karman vortex street and premixed laminar flame».Ph.D. Thesis, Lawrence Berkeley Laboratory, California, USA.

Neveu, F., F. Corbin, M. Perrin and M. Trinité (1994).Simultaneous velocity and temperature measurements in turbulent flames obtained by coupling LDV and numerically compensated fine wire thermocouple signals. $7^{\text {th }} \quad$ International Symposium on Applications of Laser Techniques to Fluid Mechanics, Lisbon, Portugal.

Nina, M. and G. Pita (1985).Measurements of fluctuating gas temperatures thermocouples. AGRAD conference proceedings, panel symposium 32.1-10, Bergen, Norway.

Paranthoen, P. and J.C. Lecordier (1996).Mesures de température dans les écouements turbulents.Revue Générale de Thermique413, 283-308.

Poireaut, B. (1997). Mécanisme de combustion dans un brûleur méthane air de type 'swirl' Influence de l'intensité de la rotation, Ph.D. thesis, University of Poitiers, France.

Rickman, D. D. and B. C. Barker (1997).Development and evaluation of armoured thermocouple fielding methods for severe blast/fragmentation environments. $43^{\text {rd International }}$

Instrumentation Symposium, Orlando, USA. 473-479.

Sbaibi, A., J. C. Lecordier and P. Paranthoen (1987).Réponse en fréquence d'un couple thermoélectrique dans un environnement radiatif ou convectif. Entropie 135, 49-53.

Scadron, M. D. and I. Warshawsky (1952).Experimental determination of the time constant and Nussell numbers for barewire thermocouples in high-velocity air streams and analytic approximation of conduction and radiation errors, Technical note 2599. National Advisory Committee for Aeronautics, Washington USA.

Shahrir A., W. H. Kurniawan and A. Shamsudeen (2008). Numerical Analysis of the Combustion Process in a Compressed Natural Gas Direct Injection Engine. Journal of Applied Fluid Mechanics, 1(2)65-86.

Tagawa, M. and Y. Ohta (1997).Twothermocouple probe for fluctuating temperature measurement in combustion rational estimation of mean and fluctuating time constants. Combustion and Flame. 109, 549-560.

Vachon, M., P. Cambray, T. Maciaszek and J.G. Bellet (1986).Temperature and velocity fluctuation measurements in a diffusion flame with large bouyancy effects. Combustion Science and Technology 48, 223-240.

Vestin, F, D. Sedarsky, R. Collin, M. Aldén, M. Linne M. and P.E. Bengtsson (2008).Rotational coherent anti-Stokes Raman spectroscopy (CARS) applied to thermometry in highpressure hydrocarbon flames. Combustion and Flame 154(1-2), 143-152.

Weckmann, E. J. and A. B. Strong (1996).Experimental investigation of the turbulence structure of medium scale 
M. S. Boulahlib and M. A. Boukhalfa/JAFM, Vol. 9, Special Issue 2, pp. 177-188, 2016.

methanol pool fires. Combustion and Flame $105,245-266$.

Xudong, X., W. C. Choi, K. Lishwar and K. Puri (2000). Temperature measurements in steady two-dimensional partially premixed flames using laser interferometric holography. Combustion and Flame 120(3), 318-332.

Yoshida, A., T. Igarashi and Y. Kotani (1997).Extinction of turbulent diffusion flames by Kolmogorov microscale turbulence. Combustion and Flame 109,
669-681.

Yuena, F. T. C. and Ö. L. Gülder (2009). Premixed turbulent flame front structure investigation by Rayleigh scattering in the thin reaction zone regime. Proceedings of the Combustion Institute, 32 (2), 1747-175.

Zhang, D. Y. and Zhou H.C. (2007). Temperature measurement by holographic interferometry for non-premixed ethylene-air flame with a series of state relationships. Fuel 86(10-11), 15521559. 